\title{
Difusión y traducción de la literatura mexicana en Checoslovaquia durante la Guerra Fría
}

\section{Introducción: escrituras de la literatura hispanoamericana en Checoslovaquia}

En el año 1506, mucho antes de que Hernán Cortés llegara a la ciudad de Tenochtitlan, apareció publicado en lengua checa en casa del tipógrafo de origen eslovaco Mikulás Bakalár, en la ciudad de Pilsen, un impreso titulado Tratado sobre las nuevas tierras y el Nuevo Mundo (Kneidl, 1981), que recogía traducciones de las primeras noticias americanas de la pluma de Américo Vespucio y Cristóbal Colón (Kašpar, 2004, 59). Como consecuencia del impulso contrarreformista durante el reinado de Felipe II, la nobleza católica centroeuropea se sintió atraída por la cultura hispánica, conservándose todavía hoy, entre otros textos, un ejemplar de la traducción al checo en 1586 de la Introducción para la sabiduría (Ad veram sapientiam introductio), de Juan Luis Vives (Uličný, 1996, 209). Durante los siglos de los virreinatos españoles en América creció el interés por las noticias que llegaban de los territorios de ultramar, como han demostrado los estudios críticos sobre la recepción de los intelectuales checos que participaron en campañas científicas americanas y escribieron crónicas de sus viajes, sobre todo en el entorno jesuita, como recogen las investigaciones de Binková (1984), de Kašpar y Fechtnerová (1988) y de Kašpar (1991, 1992, 1997).

Pese a las dificultades por las que atravesó la cultura checa en los siglos XVII y XVIII, el interés por el hispanismo se revitalizó hacia mitad del siglo XIX, cuando aparecieron publicados en lengua checa las Novelas ejemplares y Don Quijote, así como poemas principales del Romancero castellano (Uličný, 1996, 210). No obstante, fue durante el siglo XX cuando la difusión de las letras hispánicas tomó un impulso notable en Centroeuropa, desde donde se prestó especial interés a los escritores de las nuevas repúblicas americanas, que poco a poco fueron situándose en el panorama internacional tras el asentamiento de los procesos de emancipación política e intelectual. Los autores hispanoamericanos llegaron en un primer momento a territorio checo a partir de diversas traducciones al francés (Molloy, 1972) y al alemán (Rosenzweig, 2018), pero pronto se fue tejiendo una red de traductores, editoriales y revistas que asimiló e integró en la cultura checoslovaca una literatura, la latinoamericana, que

DOI:10.4312/ars.15.2.139-158 
buscaba también su identidad en un territorio europeo asolado por los conflictos bélicos y los enredos políticos que marcaron el devenir de la reflexión identitaria en buena parte del planeta.

Como se han encargado de demostrar iberoamericanistas como Hampejs (1963), y más recientemente Housková (1990), Opatrný (2002) y Montoro Cano (2014), el interés y las relaciones culturales entre el ámbito cultural checo y el hispanoamericano han sido especialmente fructíferas en la última centuria. Primero con numerosas iniciativas editoriales para la traducción y difusión de las literaturas hispánicas, pero sobre todo tras el impulso del hispanismo y el hispanoamericanismo en la academia checa a partir de los años 30 y 40ㄹ, que cristalizó en las décadas de la Guerra Fría con iniciativas como la fundación del Centro de Estudios Iberoamericanos de la Universidad Carolina y su anuario Ibero-Americana Pragensia en 1967, que todavía hoy mantienen una intensa actividad. Con el desarrollo de los estudios latinoamericanos en las universidades checas se ha ido profesionalizando una tradición de recepción también en revistas críticas y de creación, manuales universitarios y tesis doctorales que a finales de siglo, como mostró Anna Housková (1990), se antojaba ciertamente importante por la cantidad, la calidad y la diversidad de las líneas de investigación de las relaciones entre la República Checa y América Latina que no ha cesado en su desarrollo (Montoro Cano, 2014).

Las causas del impacto cultural de América Latina en Checoslovaquia atañen a diversos y complejos factores a lo largo de su historia que Gallardo-Saborido e Ilian han explicado atendiendo a la metáfora del puente plateado que utilizara Milan Kundera para narrar la complicidad existente entre «dos territorios parias» (Kundera en Gallardo-Saborido et al., 2017, 11), cuyas identidades surgieron de la represión de la Contrarreforma y el Barroco grandilocuente y se transformaron definitivamente al calor de las revoluciones políticas del siglo XX, especialmente en los años de la Guerra Fría.

Sin embargo, más allá del símbolo, como trataremos de analizar en las próximas líneas, fue en un primer momento la labor de lectura y traducción de algunos humanistas interesados en difundir la obra de los principales intelectuales latinoamericanos la que impulsó las noticias americanas en la Europa Central. Un intercambio que en muchas ocasiones fue de la mano de las diversas coyunturas sociales, como los diferentes exilios o los viajes políticos, pero que inevitablemente corrió paralelo al convulso camino institucional que se fraguó durante el siglo y que propició importantes relaciones económicas y culturales que más allá de las alianzas de poder reconectaron dos horizontes culturales aparentemente lejanos.

Las líneas que siguen se insertan en un amplio marco de revisión cultural de la Guerra Fría, que ha fijado su atención en las últimas décadas en la importancia del

1 Los primeros estudios universitarios de filología española se fundaron en 1947 en Moravia, en la Universidad Palacky de Olomouc (Housková y Soubová, 2010, 12; Zourek, 2019, 34). 
papel político e intelectual de América Latina durante el conflicto (véanse, entre otros, por ejemplo los ensayos de Alburquerque, 2011; Rupprecht, 2015; Opatrný, 2011; 2015; 2017; Zourek, 2015, 2017, 2019; Locane, 2019 o Hammond, 2020). En este sentido, situamos la argumentación de este estudio acotando las referencias geográficas, temporales e historiográficas a las relaciones literarias checo-mexicanas para trazar una panorámica de la difusión de la literatura mexicana en Checoslovaquia desde los años previos a la Segunda Guerra Mundial hasta la década de los 70, principalmente atendiendo a las obras de autores mexicanos publicadas en lengua checa durante la Guerra Fría y abrir así líneas de investigación sobre las motivaciones que llevaron a los proyectos editoriales checoslovacos a fijar su atención en determinados autores y autoras mexicanas ${ }^{2}$.

\section{Relaciones culturales entre México y Checoslovaquia durante la Guerra Fría}

Antes de abordar los procesos de producción y traducción de obras mexicanas difundidas en Checoslovaquia durante la Guerra Fría es conveniente revisar el contexto de las relaciones entre ambas geografías, trazando dos caminos paralelos que aunque mantienen una estrecha relación no siempre fueron dependientes. En este sentido, la revisión historiográfica apunta por un lado a las relaciones institucionales de los dos países, llenas de encuentros y desencuentros, pero también hacia una serie de claves de producción y recepción del horizonte cultural mexicano (editoriales, viajes institucionales, revistas, colaboración universitaria, exposiciones artísticas) sin las que no podemos entender el inicio de la traducción al checo de la literatura mexicana.

En el campo de la política exterior los estudios colectivos que han indagado en los archivos gubernamentales (véanse, por ejemplo, Las relaciones checo-mexicanas, Opatrný, 2011; Checoslovaquia, Guatemala y México en el Período de la Revolución Guatemalteca, Perutka, 2014 o Las relaciones entre Checoslovaquia y América Latina 1945-1989 en los archivos de la República Checa, Opatrný et al., 2015) señalan la sinuosidad de un camino marcado por las diversas tendencias ideológicas de los presidentes mexicanos, por los volantazos políticos en Checoslovaquia y por el papel de los acuerdos comerciales.

Las relaciones culturales fueron construyéndose progresivamente en los dos continentes en un primer momento en torno a los intelectuales antifascistas, sobre todo por las acciones de los exiliados checoslovacos tras la ocupación alemana. Tras el triunfo comunista en Checoslovaquia, Praga se convirtió en un importante centro

2 También fueron muchos los intelectuales checos que viajaron a México y que escribieron ensayos divulgativos o textos literarios ambientados en espacios e historias propiamente mexicanas. Se puede abrir aquí otra interesante línea de trabajo sintetiza, entre otras, Gloria Cejka Luna (2003). 
de la propaganda cultural del bloque socialista y el punto de entrada a la Unión Soviética, lo que motivó que numerosos intelectuales latinoamericanos que realizaron viajes oficiales atraídos por el impulso de la lucha política escribieran sobre su estancia en el país.

Pese al convulso vaivén político, desde la década de los años 20 las relaciones políticas, económicas y culturales de México con Checoslovaquia han sido las más fructíferas de todas las entabladas con los países de la Europa Central y del Este. Desde la apertura del Consulado General de México en Praga en 1922 y del Consulado General de Checoslovaquia en México, la labor diplomática de personajes como Vlastimil Kybal (1935-1939) ${ }^{3}$ fue fundamental para el desarrollo de las relaciones bilaterales. El gobierno aperturista de Lázaro Cárdenas (1934-1940) mantuvo una relación excelente con Tomás Garrigue Masaryk, presidente checoslovaco, cuestión que se vio reflejada entre otras acciones en la creación de la Sociedad de Amigos de Checoslovaquia, en la adquisición de libros para la Biblioteca Nacional de México o en el fructífero intercambio cultural en el ámbito artístico, con la llegada de intelectuales como Koloman Sokol y la fundación de Taller de Gráfica Popular, escuela de arte que mantuvo relaciones con los artistas de la Unión Soviética y los países del Bloque del Este (Fernández Montes, 2014). En Praga, por su parte, se realizaron diferentes actividades culturales relacionadas con México en estos años, como una exposición de arte popular mexicano y se inauguró la sección mexicana del Instituto Español e Iberoamericano (Opatrný et ali, 2015, 120).

El nuevo orden político surgido tras la II Guerra Mundial y el golpe comunista en Checoslovaquia en 1948 acrecentó una polarización que obligó a los diferentes presidentes mexicanos a posicionarse. El pragmatismo comercial de Miguel Alemán no ocultó la pugna ideológica contra la influencia del general Cárdenas, cuyas apariciones públicas en favor del movimiento comunista internacional fueron combatidas desde el gobierno y la prensa conservadora (Servín, 2004). También en el sexenio de Adolfo Ruiz Cortínez se mantuvo el apoyo institucional al anticomunismo norteamericano, con sonados episodios como el de la publicación en el diario Excelsior de una lista de 143 personajes públicos a los que se les acusaba de ser partidarios del comunismo, tras aparecer la bandera roja del Partido Comunista cubriendo el ataúd de Frida Kahlo en el Palacio de Bellas Artes (Opatrný et ali, 2015, 126).

No obstante, durante estos años se desarrolló una intensa actividad pro-socialista en México en torno sobre todo al Partido Comunista de México, que extendió sus vínculos internacionales (con muchas disputas ideológicas) tras la fundación del Consejo Mundial de la Paz, quizá el órgano de propaganda cultural más importante del bloque soviético (Fernández Montes, 2014; Crespo, 2016). En 1949, en el

3 Dejó constancia de sus viajes en algunos textos (Bartecek, 2004). 
Congreso celebrado en paralelo en París y en Praga se estableció la creación de un Comité Mundial de Partidarios de la Paz. El órgano fue recibido con entusiasmo por los intelectuales de la izquierda latinoamericana y especialmente en México tuvo una aceptación al máximo nivel, con intelectuales como el mismo Lázaro Cárdenas, Enrique González Martínez o Efraín Huerta jugando un papel notorio en la entidad, tanto en la celebración de encuentros en México (en septiembre de 1949 se celebró el Congreso Continental Americano por la Paz), como en viajes políticos hacia Praga y los países socialistas para conocer de primera mano el funcionamiento cultural del otro lado del Telón de Acero.

A partir de 1957, la aparente distensión tras la muerte de Stalin y el cambio de rumbo de la política exterior durante el sexenio de López Mateos mejoró notablemente la relación bilateral con la reapertura de las Embajadas, con la creación del Instituto checoslovaco-mexicano en México y con la institucionalización de un programa de becas para estudiantes mexicanos por parte del gobierno checoslovaco. México tuvo un papel activo en la defensa de la neutralidad tras la invasión en Playa Girón y gracias a la inteligencia checoslovaca la prensa mexicana publicó el telegrama del presidente checoslovaco Antonín Novotny (Opatrný et ali, 2015, 126) donde se justificaba la defensa de la autonomía del gobierno cubano por parte de las instituciones del país europeo.

Pese al carácter reaccionario del gobierno de Díaz Ordaz, la década de los 60 estrechó los lazos de colaboración cultural. En 1965 y 1966 se firmaron acuerdos de cooperación universitaria tras la visita a Praga del ministro de Educación de México, el escritor Agustín Yáñez, momento en el que se impulsó también un acuerdo de cooperación cultural que entró en vigor en 1970. Durante estos años se institucionalizaron los estudios culturales iberoamericanos en Checoslovaquia y una vez superadas las revueltas políticas del 68 se firmaron los principales acuerdos bilaterales en materia comercial, de telecomunicaciones y también en ciencia.

Entre otros trabajos, las monografías de María Eugenia Mudrovcic (1997), Rupprecht (2015), Germán Alburquerque (2017) o Michal Zourek (2019) han abierto camino a una interesante línea de investigación que sitúa el foco en el análisis de los textos de los protagonistas de los procesos culturales surgidos en estos años. Zourek $(2015,2017,2019)$ basa su argumentación en torno a los lazos culturales entre América Latina y Checoslovaquia, demostrando en sus diferentes estudios cómo la propaganda cultural del bloque soviético convirtió la ciudad de Praga en un centro de encuentro de la intelectualidad mundial afín al socialismo a través del impulso editorial, los viajes políticos y el intercambio artístico, con diferentes proyectos y exposiciones museísticas y la potenciación de los festivales de cine.

La instrumentalización política durante los primeros años de la Guerra Fría absorbió la potente industria editorial en Checoslovaquia, poniéndola al servicio del 
Estado (Zourek, 2019, 31). El interés por la literatura latinoamericana había comenzado en décadas anteriores y en el caso de México hubo una importante recepción de la literatura relacionada con la Revolución. En 1961 se publicaban en Checoslovaquia diez periódicos en lengua española, la Revista Internacional: Problemas de la Paz y el Socialismo circuló entre 1958 y 1990 y desde 1937 Radio Praga emitía noticiarios en español que se mantuvieron también tras la II Guerra Mundial.

Además, antes del golpe comunista, Checoslovaquia contaba con una serie de iniciativas vinculadas a la edición literaria y la lectura interesadas en la traducción de obras europeas y americanas que fueron absorbidas por el régimen político a partir de 1948 (Halada, 2007). En este sentido, destaca la organización cultural cooperativa Družstevní Práce (DP), receptora de la vanguardia checa y vinculada al mundo del diseño a través de su revista (1922-1957) (Sudek et ali, 2006), que llegó a publicar la traducción de El águila y la serpiente, de Martín Luis Guzmán en 1947, antes de ser absorbida por la editorial estatal SNKLHU (Editorial Estatal de Bellas Literaturas, Música y Arte) a finales de 1952.

Entre 1935 y 1949 se desarrolló la aventura editorial Europský literární klub (Club Literario Europeo), fundada en Praga por los editores Bohumil y Ladislav Janda (Bilková, 1994) que llegó a alcanzar los cien mil socios en 1945. La editorial publicó 160 títulos de autores extranjeros, entre ellos algunos narradores mexicanos contemporáneos, como Gregorio López Fuentes y Mauricio Magdaleno.

El hispanista y traductor Zdeněk Šmíd relata su relación con el editor Jan V. Pojer, fundador de la editorial Atlantis en 1928. El sello de Brno funcionó hasta 1948 y publicó traducciones de autores extranjeros, entre las que destacan adaptaciones de Šmíd de Ventura García Calderón, Alfonso Reyes o Miguel de Unamuno (Rosenzweig, 2014, nota 54).

Uno de los proyectos editoriales más potentes de la época fue el de la editorial Odeon, fundada por Jan Fromk en 1925, que tuvo entre sus especializaciones la traducción de ficción extranjera de calidad, heredando la colección World Reading que había iniciado la editorial Svoboda en 1948. En 1949 la editorial fue también nacionalizada y pasó a formar parte importante de la editorial estatal, que se acabó renombrando como Odeon a partir de 1966.

El proyecto editorial Julius Albert (1925-1949) puso su foco en las traducciones del inglés, el francés y el español, con colecciones de novela negra, westerns, novela erótica y biografías que fueron liquidadas en 1949, tras la publicación de más de 350 títulos. Una de las iniciativas, de la mano de Otakar Štorch-Marien, fue la de promover la publicación de prosas contemporáneas representativas, en cuyo catálogo aparece la primera traducción de Los de abajo, de Mariano Azuela, en 19354.

4 Para los datos bibliográficos completos de las ediciones checoslovacas son magníficos los catálogos que proporcionan Uličný (2005), Rosenzweig (2018) y Mamasalieva (2020). 
Uno de los grupos mediáticos más importantes en el siglo XX checoslovaco fue la editorial Melantrich, fundada en 1897. Durante los años 20 y 30 se expandió en el mundo cultural checoslovaco a través de periódicos, revistas e inversiones en el mundo cinematográfico. El grupo fomentó la publicación de algunas colecciones relacionadas con la ficción extranjera, en cuyo catálogo se cuentan autores mexicanos como Martín Luis Guzmán, con La sombra del Caudillo, de 1937, y En la rosa de los vientos, de José Mancisidor, en 1949. Fue también nacionalizada con la llegada al poder de los comunistas en 1948 y mantuvo sus actividades hasta 1999.

Otra de las líneas editoriales más interesantes de este periodo lo conforman los diferentes catálogos de la editorial Svoboda, creada en 1945 en la órbita del Partido Comunista. Fue un órgano de intercambio literario para la ficción política en el que se publicaron un amplio abanico de obras de diferentes géneros, como el policial o la ciencia ficción, y en el que tuvieron cabida colecciones como la ya citada World Reading (1948-1953) y como la colección Omnia, que publicó más de 300 traducciones entre 1967 y 1996 (Halada, 2007).

Como recoge Miloslav Uličný (2005, 275-291), entre 1935 y 1949 se tradujeron al checo ocho novelas mexicanas, más otras dos que anota Zourek hasta 1959 (2019, 36-39). Entre 1945-1959, el periodo conocido como la Guerra Fría de los intelectuales (Ory en Zourek, 2019, 19) se publicaron 52 libros de autores latinoamericanos en lengua checa $(2019,35)$, todos ellos vinculados al movimiento comunista y caracterizados por su estética realista, muchas veces modificados en sus traducciones para ajustarse a la línea oficial. La propaganda checoslovaca ofrecía tiradas amplias que superaban incluso a las de las ediciones en español, como los 13.000 ejemplares que se tiraron en 1949 de la traducción de la novela En la rosa de los vientos, de José Mancisidor, con la gran capacidad de medios con los que contaba el grupo Melantrich. Los derechos de autor apenas si tenían recompensa, para sorpresa de muchos, como Nicolás Guillén, que perdió sus 200 dólares por la prohibición de la divisa por parte del gobierno Checoslovaco en 1949, o Pablo Neruda, quien en 1956 escribía a Jan Drda reclamando que le enviaran a Chile un automóvil Skoda por los derechos de autor de su obra (Zourek, 2019, 38-39).

Lo cierto es que como demuestra la publicación de la correspondencia entre Alfonso Reyes y Zdeněk Šmíd, editada por Gabriel Rosenzweig (2014), los contactos entre los escritores y los traductores y las editoriales se llevó a cabo en numerosas ocasiones a través de iniciativas que partieron de la inquietud de los intelectuales checos interesados por la literatura latinoamericana, que escribían cartas a los escritores y a terceros pidiendo por un lado que les enviaran los libros y por otro solicitando el permiso para poder desarrollar las traducciones.

Otro de los puntos de entrada de la literatura mexicana a Checoslovaquia durante estos años fue la revista Literatura Mundial (Světová literatura), que se editó 
desde 1956 como parte del proyecto editorial estatal SNKLHU y que mantuvo su actividad hasta 1996. La revista fue sin duda el espacio más activo para la difusión de la literatura extranjera en Checoslovaquia en la segunda mitad del siglo XX y por sus páginas circularon traducciones de los principales escritores del mundo, artículos críticos, reflexiones filosóficas y ensayos sobre arte, cine y arquitectura. La literatura latinoamericana fue protagonista de muchas de las traducciones propuestas por la revista. Así, por ejemplo, el número 3 del año 1963 estuvo dedicado en gran parte a la literatura mexicana, con una exposición general de José Luis Martínez titulada «Las corrientes principales de la literatura mexicana contemporánea» y una breve antología de poetas contemporáneos mexicanos preparada y traducida por Ivan Slavík, entre los que destaca Octavio Paz (Volek, 1973, 266). También Carlos Fuentes vio publicadas sus primeras traducciones al checo en la revista en 1965, que eligió la novela corta Aura (publicada originalmente en 1962), para presentar a Fuentes en el panorama literario checo.

Otra de las puertas principales de entrada de la literatura mexicana en Checoslovaquia fueron los viajes institucionales de muchos intelectuales atraídos por las novedades políticas que llegaban desde la Europa del Este. En 1927 visitaron la Unión Soviética Diego Rivera y David Alfaro Siqueiros y en las décadas siguientes un gran número de intelectuales mexicanos viajaron a la Europa Central y del Este. Entre otros, Vicente Lombardo Toledano, Víctor Manuel Villaseñor, José Mancisidor en los años 30, o Manuel Maples Arce, que fue embajador en Praga entre septiembre de 1943 y marzo de 1944. El circuito se fue conformando a partir de iniciativas como el Festival de Cine de Karlovy Vary, que abrió su escena al séptimo arte latinoamericano en la década de los 50 (Zourek, 2015, 120) y que premió trabajos del camarógrafo mexicano Gabriel Figueroa en películas como Río escondido (1949), Maclovia (1949), Pueblerina (1950), o Cananea (1978). En los 50 visitaron los países soviéticos artistas como el mismo Figueroa, José Revueltas o Efraín Huerta. Destaca en este sentido el caso del poeta mexicano, que viajó hasta en tres ocasiones al viejo continente, dejando constancia literaria de su experiencia en los versos de Los poemas de viaje (1949-1953) donde escribió varios poemas dedicados a Checoslovaquia. Ya en los 60 y 70, la intensificación de las relaciones bilaterales promovió visitas institucionales como la de la legación encabezada por el escritor Agustín Yáñez, ministro de Educación en el sexenio de Díaz Ordaz, Carlos Fuentes, cuya obra supuso un gran éxito en los países de Europa del Este, Rodolfo Usigli y Emilio Carballido, que asistieron a los estrenos de sus adaptaciones teatrales en Checoslovaquia o las escritoras Marcela del Río, que fue agregada cultural en Praga entre 1972-1977 y ha publicado recientemente una novela ambientada en la época, La cripta del espejo (2019), y María Luisa Mendoza, que recogió sus experiencias en los reportajes publicados en el volumen Ra, Re, Ri, Ro, Rusia! La URSS (1974). 


\section{La literatura mexicana en Checoslovaquia durante la Guerra Fría}

Para abordar el estudio de las traducciones al checo durante este periodo contamos con el magno catálogo crítico realizado por Miloslav Uličný, Historia de las traducciones checas de literaturas de España e Hispanoamérica (2005) y actualizado en posteriores publicaciones (Uličný, 2010), que ha abierto la puerta al estudio historiográfico y comparativo de las traducciones (Rosenzweig, 2018), al trabajo de vaciado de archivos y prensa de la época y a la búsqueda de las misivas entre traductores y escritores para entender mejor los características y los interrogantes de la recepción de la literatura hispánica en Checoslovaquia. En las líneas que siguen recogemos las diferentes informaciones sobre los títulos publicados de autores mexicanos en Checoslovaquia en los diferentes géneros literarios apuntando hacia posibles líneas de interpretación que pueden llevarnos a trabajos futuros.

La labor de Gabriel Ronsenzweig $(2014 ; 2018)$ en estos archivos públicos y personales ha cristalizado en la edición de la correspondencia entre el escritor mexicano Alfonso Reyes y su traductor, Zdeněk Šmíd y en un trabajo reciente sobre la historia de las primeras traducciones de novela mexicana en Checoslovaquia. La narrativa mexicana empezó a conocerse en la década de los 30 y los 40 y mantuvo su interés con el cambio de régimen también en los 50 y los 60, sobre todo aquellas obras que escribieron la Revolución mexicana. La correspondencia es un relato de época fantástico para comprobar el interés creciente de la literatura hispánica en el ámbito cultural checoslovaco de estos años, a través del trabajo entusiasta de figuras como Zdeněk Šmíd, dedicado a la lectura, la importación de libros y la traducción de autores españoles e hispanoamericanos. El enorme catálogo de las traducciones literarias españolas e hispanoamericanas de Šmíd publicado por Rosenzweig (2014, anexo 1) recoge las referencias americanas de obras como Don segundo sombra, de Ricardo Güiraldes (1936), Barrabás y otros relatos, de Arturo Uslar Pietri (1940), Raza de bronce, de Alcides Arguedas (1945), El caballo y su sombra, de Enrique Amorim (1950), El éxodo de Yangana, de Ángel Felicísimo Rojas (1960), El mundo es ancho y ajeno, de Ciro Alegría (1969), El señor presidente (1971) y Hombres de Maíz (1981), de Miguel Ángel Asturias.

Sobre narrativa mexicana, Zdeněk Šmíd llevó a cabo las traducciones de Alfonso Reyes, en una obra publicada en 1937 en la editorial Atlantis, que tituló Tríptico: La saeta-Visión de Anáhuac-La caída, en la que se recogían las tres obras. En el mismo año, Melantrich había publicado su traducción de La sombra del caudillo, de Martín Luis Guzmán, con el título de Lluvia sangrienta. Sobre la novela, escribe el traductor: «contiene, en mi opinión, las mejores páginas de psicología política que uno pudiera leer últimamente». Hasta el cambio de régimen en Checoslovaquia se publicaron, además de las traducciones de Šmíd, las novelas Los de abajo, de Mariano Azuela (1935), 
traducida por Jindřich Kubíček, con prólogo de Francisco Ortiz Monasterio (Šmíd afirma haberla publicado en un periódico en el mismo año en una carta a Alfonso Reyes, aunque Uličný no la ha localizado y considera que no se publicó (Rosenzweig, 2014, [9]), El indio (1941) y Mi general (1941), de Gregorio López y Fuentes, El resplandor (1946), de Mauricio Magdaleno, El águila y la serpiente (1947), de Martín Luis Guzmán y En la rosa de los vientos (1949), de José Mancisidor, todas ellas relacionadas con la Revolución mexicana. Sobre la traducción de esta última, realizada por Kuchválek y Patava, Uličný $(2005,80)$ afirma que «en la traducción hay algunos calcos y no pocos diálogos suenan demasiado enfáticos. El epílogo de los traductores rebosa de frases anticapitalistas, antiimperialistas y de lucha de clases».

Las traducciones sobre narrativa latinoamericana aparecidas en estos años sugieren un interés importante entre los intelectuales checoslovacos en las líneas novelísticas relacionadas con el indigenismo y en el caso mexicano con las novelas que contaron al mundo la compleja Revolución iniciada en 1910 (Uličný (2005, 73-92). En este sentido, se abre un espacio de investigación sugerente sobre las posibles concomitancias ideológicas, identitarias y estéticas que encontraron las novelas de la tierra, las reivindicaciones indigenistas o los postulados revolucionarios mexicanos en la compleja fluctuación cultural de los países del Bloque del Este, que necesariamente habrá que abordar en futuros trabajos.

Tras el final de la II Guerra Mundial siguieron traduciéndose escritores y obras afines ideológicamente al socialismo imperante en la Europa Central, como muestran las referencias recogidas por Uličný (2005). En la década de los 50 y los 60, el interés político de traductores como Kuchválek y Patava fue de la mano de propuestas menos cercanas a las derivaciones ideológicas contemporáneas y de rescate del pasado, como la de la traducción de la Brevísima relación de la destrucción de las Indias, de Bartolomé de las Casas, realizada en 1954 (Uličný, 2005, 82), o la versión de los poemas mexicas de la visión de los vencidos que circularon en México durante estos años y que llevó a cabo en 1969 Ivan Slavík, quien tradujo también el Popol Vuh en 1976. Pese a la reedición de obras como Los de abajo (1964), con el título en checo de Soldados de la pobreza, no todas las traducciones partieron de posiciones políticas. La traducción de los cuentos de Juan Rulfo, Llano en llamas, se llevó a cabo en 1964 por V. Kajdos y las cartas de Šmíd a Alfonso Reyes desvelan las inquietudes del traductor por conocer y encontrar también obras de calidad, reflejo de la realidad cultural mexicana y latinoamericana. Es interesante comprobar cómo el intelectual checo reclamaba constantemente a Alfonso Reyes el envío de libros en español sobre literatura hispanoamericana, por un lado, y el contacto de escritores mexicanos que pudieran facilitarle sus obras, por otro. Los libros fueron llegando a Checoslovaquia con generosidad, sobre todo desde que Reyes se hiciera cargo de El Colegio de México. El interés de Šmíd por conocer con amplitud la literatura hispanoamericana se muestra por ejemplo en la petición de 
la Historia de la literatura hispanoamericana de Imbert, que Reyes le envía en 1954. Además, Alfonso Reyes le facilita las direcciones de Monterde, de Jimenéz Rueda, de Torres Bodet y le habla en 1956 de un joven escritor llamado Carlos Fuentes: «Es mejor que pida Ud. documentos literarios mexicanos (invocando mi nombre) al Sr. Carlos Fuentes (joven escritor) Fundición 44-4, México, 5, D. F.» (Alfonso Reyes en Rosenzweig, 2014, [48]), a los que Šmíd escribe también con entusiasmo.

Las traducciones de Carlos Fuentes aparecieron con fuerza en el panorama editorial checoslovaco en la década de los 60, con la publicación de la novela corta Aura en la revista Literatura mundial en 1965 y las tiradas de la editorial Odeon de La región más transparente y de la editorial Mladá fronta de La muerte de Artemio Cruz, en traducción de Hana Posseltová en 1966. Fuentes conoció en París a Milan Kundera en 1968, año de las revueltas estudiantiles y de la Primavera de Praga, sobre las que escribió algunos artículos que recogió en el libro Los 68: París, Praga, México (2005). En diciembre de ese mismo año llegaron a Praga, invitados por Kundera, Carlos Fuentes, Gabriel García Márquez y Julio Cortázar, como recuerda el escritor mexicano en los textos «La ciudad de Kafka y de Kundera: Praga y sus fantasmas» (1981) y «Sobre Julio Cortázar» (2000), con el ánimo de apoyar el «socialismo de rostro humano» (2000) del gobierno de Dubcek tras la intervención soviética del 68. El relato de los días de los tres grandes escritores en Praga se entremezcla con la interpretación de los personajes de Kafka y de Kundera y de la situación que está viviendo Checoslovaquia: «No hay ciudad más hermosa en Europa», (1981, 52), escribe Fuentes, pero «la habitan demasiados fantasmas» $(1981,52)$. En la semblanza «Sobre Julio Cortázar» publicada en el diario La Nación en el año 2000, Fuentes recuerda los días en Praga y su sorpresa al escuchar un disco de Lola Beltrán en las fábricas checas:

La mala pasada que me jugaron Gabo y Julio, invitados por Milan Kundera a oír un concierto de música de Janacek, mientras yo era enviado con la representación de mis amigos a hablarles de Latinoamérica a los obreros metalúrgicos y a los estudiantes trotskistas. "Che, Carlos, a ti no te cuesta hablar en público; hacelo por Latinoamérica ...». Algo gané, musicalmente. Descubrí que en las fábricas checas, para aliviar el tedio estajanovista de los trabajadores, los altavoces tocaban el día entero un disco de Lola Beltrán cantando «Cucurrucucú, paloma». Lo recuerdo. (Fuentes, 2000)

Por otro lado, el discurso que construyen las misivas de Šmíd y Alfonso Reyes muestra el interés del traductor por enseñar también al público checoslovaco literatura dramática y lo cierto es que la recepción del teatro mexicano en lengua checa tiene un recorrido interesante durante estos años. El teatro novohispano había llegado a Checoslovaquia en la década de los 50 a partir de las traducciones, adaptaciones y estrenos de 
algunas obras del teatro clásico firmadas por Juan Ruiz de Alarcón, como El tejedor de Segovia, traducida por Olga Fischerová y estrenada el 9 de marzo de 1956 en el Teatro de Bohemia, en Liberec. Además, Vladimir Brusinský tradujo la obra más valorada del autor, La verdad sospechosa, que se estrenó en Plzeň en 1958 (Mamasalieva 2020, 13).

Ante la insistencia de Šmíd, Alfonso Reyes le ofrece el contacto de Rodolfo Usigli, a quien escribe en 1958. El dramaturgo mexicano responde dudando de que «Corona de sombra pudiera interesar al público de Checoslovaquia por la interpretación no convencional de las figuras de Maximiliano y Carlota» y porque «la memoria de los Habsburgo no puede ser grata en Checoslovaquia» (Rosenzweig, 2014 [37] y [38] nota 181) y le ofrece enviarle ejemplares de Otra primavera, Jano es una muchacha, La familia en casa, El niño y la niebla y La función de despedida. No obstante, no será hasta algunos años más tarde cuando el dramaturgo Jan Makarius adaptara al checo El gesticulador, una de las obras principales de Usigli, que se estrenó en 1966 con motivo de la visita de la delegación mexicana del ministerio de Cultura de Agustín Yáñez en el Teatro Silesiano Zdeněk Nejedlý en la ciudad de Opava. Al estreno acudió el propio Usigli y el embajador mexicano Alfonso Castro Valle (Mamasalieva, 2000, 19). Eva Mamasalieva $(2020,17-19)$ propone una interesante argumentación sobre la recepción de la obra, sobre la que se publicaron al menos siete artículos en la prensa checoslovaca, destacando el «hecho inesperado» de que una obra con el fuerte contenido de crítica política como la que propone El gesticulador pasara por las tablas en los años del régimen comunista $(2020,20)$. Uličný anota que Makarius adaptó también de Usigli $E l$ circo del mundo, que aunque no pasó por las prensas se representó en 1978.

En los años 60, junto con su esposa Jana, el matrimonio Makarius adaptó dos obras de Federico S. Inclán, que visitó el país también en el año 1966. La primera, Cada noche muere Julieta (1963), había sido estrenada en México en 1960 con muy malas críticas (Ugarte, 1971) y fue adaptada y publicada solo tres años después al checo con el título Romeo y Julieta hoy no actúan por la editorial Dilia. En 1965, en la misma colección, apareció publicada la adaptación de Una noche con Casanova, pieza cómica basada en un cuento de Stefan Zweig que revisita con poco éxito las aventuras del personaje clásico.

Otros de los grandes nombres de la primera dramaturgia especializada de México pertenecientes a la Generación del Medio Siglo tuvieron resonancia y adaptaciones en los teatros checoslovacos durante los años 60 y 70. Es el caso por ejemplo de Rafael Solana, intelectual comprometido con el desarrollo del teatro mexicano que había formado parte de la fundación de la revista Taller, junto a Octavio Paz. En 1963, la editorial Dilia publicó su obra más conocida, Debiera haber obispas, adaptada por Juan E. Bécquer y Maurice P. Wahl y traducida por Ladislaw Walló, y en la misma editorial apareció en 1965 Ensalada de Nochebuena, en traducción de Marie Effenbergerová. 
La adaptación del teatro mexicano en Checoslovaquia funcionó bien durante estos años como celebración en las visitas de las legaciones diplomáticas, como ocurrió con la visita oficial de Agustín Yáñez en 1966. En este sentido, la puesta en escena de obras mexicanas en Checoslovaquia tuvo un impulso importantísimo con la llegada de la escritora Marcela del Río como agregada cultural de México entre 1972 y 1977. Del Río se había formado en Arte Teatral en el Instituto Nacional de Bellas Artes y es sin duda una de las voces destacadas de la dramaturgia mexicana contemporánea. Su estancia en Praga en la diplomacia mexicana motivó entre otras cosas la escritura de Compendio sobre Checoslovaquia, la llegada de la exposición «Tres mil años del arte mexicano" y la propuesta de montaje de diez obras de teatro mexicano para la compañía nacional checa. De esta forma, pasaron por las tablas checas en los años 70 algunas obras de autores de la Generación de los 50, como Emilio Carballido, cuyo éxito en los teatros mexicanos se exportó a un importante número de países, también Checoslovaquia. El propio Šmíd tradujo y publicó en la editorial Dilia en 1963 la primera traducción de Carballido, versionando Un pequeño día de ira y en 1974 se estrenó El relojero de Córdoba en el Teatro Na Vinohradech en adaptación de Vladimír Horáček. La obra, compuesta en Praga (Socorro Merlín), tuvo una resonancia importante en la prensa nacional (Mamasalieva, 2020, 37). Se conserva un dibujo del diseño escénico del reloj y el folleto de mano con una contribución sobre el teatro mexicano de Marcela del Río (Mamasalieva, 2020, 38). En ese mismo año, el matrimonio Makarius adaptó también Silencio, pollos pelones, ya les van a echar su maíz.

Durante la época de Marcela del Río se llevaron también a las tablas las obras de Maruxa Vilalta, Esta noche juntos, amándonos tanto, en adaptación de Horáček, en 1974, y la pieza de Federico S. Inclán, Cada noche muere Julieta, que fue estrenada en el Teatro Nacional de Ostrava el 23 de noviembre de 1976 (Mamasalieva, 2020, 43). Interesó su mensaje político, adaptado al gusto e ideología del público checoslovaco (Mamasalieva, 2020, 44). La escenificación se realizó en forma de comedia musical, «llena de danzas, de cantos con guitarra, de humor popular y con vestuario colorido (Mamasalieva, 2020, 44). La misma fórmula se utilizó para la adaptación de La fiesta del mulato, de Luisa Josefina Hernández el 31 de marzo de 1977, en el mismo teatro en el que se había estrenado El relojero de Córdoba. La obra, adaptada por Milan Clábek y dirigida por M. Vildman en forma de obra musical se tituló Fiesta del monte de plata. La cronología de la web de Marcela del Río apunta también hacia la adaptación de Los argonautas, de Sergio Magaña, sobre la que no dan noticias Uličný (2005) ni Mamasalieva (2020).

También la poesía mexicana ha formado parte de los catálogos de traducciones checoslovacas a lo largo del siglo XX, aunque el número de publicaciones es mucho menor que en el caso de la narrativa o del teatro. Apunta Uličný $(2005,139)$ que los primeros versos mexicanos volcados al checo aparecen en 1907, en la revista Květy una antología preparada por Antonín Pikhart con diez poetas mexicanos (Manuel Acuña, 
Balbino Dávalos, Salvador Díaz Mirón, Manuel Gutiérrez Nájera, Fernando Luna, José M. Pino, Ignacio Ramírez, Antonio Zaragoza, Eduardo Zárate y Rafael Zayas). No hay más noticias registradas hasta 1943, cuando en la antología Poesía de héroes y santos de Olga Franková y Jan Fischer se incluyen como poetas españoles las traducciones de poemas de Jaime Torres Bodet, Manuel Gutiérrez Nájera y Amado Nervo. Durante los años 40 y 50 se publicaron traducciones de poetas comprometidos políticamente, como Pablo Neruda, Rafael Guillén, José Martí o César Vallejo, pero no hay noticias de poesía mexicana hasta la década de los 60 y los 70, en las que se producen algunos hitos interesantes.

Por un lado, la nueva poesía mexicana desembarca en Checoslovaquia en 1963, en una antología traducida por Ivan Slavík para el número 3 de la revista Literatura Mundial. El especial de poesía mexicana, encabezado por un panorama crítico de José Luis Martínez, está conformado por las traducciones de hasta 18 poetas mexicanos, entre los que destacan Ramón López Velarde, Carlos Pellicer, José Gorostiza, Alfonso Reyes, Octavio Paz o Rosario Castellanos.

Por otro lado, la obra de Octavio Paz tuvo un papel destacado en el desarrollo de las traducciones latinoamericanas en Checoslovaquia. El Premio Nobel fue el único poeta mexicano del que se tradujo un libro completo en estos años. Emil Volek (1971) dedicó una semblanza a la recepción de Octavio Paz en Checoslovaquia, en la que destaca su papel axial en la antología de Literatura mundial de 1963. Además del poema «Fábula», traducido por Ivan Slavík, apareció un fragmento de reflexión sobre la mexicanidad incluida en El laberinto de la soledad titulado «Todos Santos, Día de muertos», en traducción de Kamil Uhlír, junto con unas imágenes de unas máscaras mexicanas y un texto del escritor checoslovaco Norbert Fryd titulado «La magia de las máscaras» (Volek, 1971, 266). En el mismo año, en el número 6, la revista publica un panorama de la poesía latinoamericana de Fernández Retamar, acompañado de una antología de la que forma parte el poema de Paz «Himno entre ruinas», traducido por Lumír Civrny. En 1966 se publica el final de Piedra de sol en el semanario Literarni noviny (Volek, 1971, 267) y un conjunto de versos con el título de Na brehu sveta (A la orilla del mundo) en la colección de poesía de la editorial nacional SNKLU, preparada y traducida por Lumír Civrny, que coinciden con la última parte de la antología Libertad bajo palabra, que había sido publicada en 1960. El mismo Civrny preparó un programa de radio con recitado y comentario de algunos poemas en 1969, titulado «Viento entero, de visita en el taller poético de Octavio Paz» (Volek, 1971, 267).

Por último, me gustaría terminar esta panorámica de la literatura mexicana en Checoslovaquia aludiendo a las diferentes antologías de poesía indígena que aparecieron publicadas en la década de los 70. Uličný $(2005,150)$ y Housková $(1990,304)$ recogen hasta tres publicaciones en las que los versos precolombinos son los protagonistas. En 1974 se tiraron 7.000 ejemplares de una colección titulada «Una mariposa 
de obsidiana», publicada por Mladá fronta y preparada y traducida por Ivan Slavík, que como hemos dicho, pasó por las prensas también una traducción del Popol Vuh en 1976. En 1974 se publican 12.000 ejemplares de La danza de los elementos, una antología de poesía náhuatl que tradujo del castellano y de editó Frantisek Vrhel. Además, en 1977 Melantrich publica 2.000 ejemplares de El vaho sobre el abanico, una selección de poesía precolombina preparada por Miguel Ángel Asturias y traducida por Vlastimil Marsiček. Sobre la importancia del descubrimiento de los textos precolombinos en México en la década de los 60 y los 70, con el tamiz de los trágicos acontecimientos de Tlatelolco en 1968, da cuenta un estudio reciente (Sanchis Amat, 2020) que apunta hacia la reinterpretación del legado indígena en el debate identitario del México contemporáneo. Es interesante a este respecto que la traducción de los textos editados por Ángel María Garibay y Miguel León-Portilla a finales de los años 50 llegara de manera tan temprana a la Europa Central, muestra del interés etnológico, pero también político, de unos textos que estaban jugando un papel central entre la intelectualidad mexicana del momento.

\section{Conclusiones y líneas de investigación}

Como hemos tratado de señalar en estas líneas, la difusión y traducción de la literatura mexicana en Checoslovaquia durante los años de la Guerra Fría fue notable y creciente debido principalmente al interés de diferentes humanistas, al afianzamiento de la academia hispanoamericana en el país y a las estratégicas relaciones institucionales que se fraguaron en unas décadas en las que ambos países necesitaron de la influencia internacional para asentar su maquinaria de Estado.

Las obras de los escritores mexicanos llegaron a Checoslovaquia a través de proyectos editoriales, festivales de cultura o viajes institucionales a partir sobre todo de la década de los 30 y en torno principalmente a las noticias literarias que revisaban el compromiso con la Revolución mexicana. En las décadas siguientes, y con la llegada al poder del régimen comunista, se fomentó un intercambio cultural de corte ideológico, que sobre todo en la narrativa llevó a las prensas checoslovacas obras y autores comprometidos políticamente. El sentido social de la Revolución mexicana interesó a los revolucionarios centroeuropeos, que vieron con buenos ojos unas historias y unos intelectuales que defendían proyectos que, alejados en sus contextos nacionales, coincidieron en algunas de sus líneas maestras. El teatro fue de la mano de las relaciones institucionales y funcionó notablemente como aderezo de los encuentros y visitas bilaterales. Las piezas teatrales adaptadas y estrenadas en Checoslovaquia se ajustan a las dos líneas principales del nuevo régimen dominante. Por un lado, las obras de corte político, siempre revisadas y preparadas para el contexto checoslovaco, y por otro, las representaciones de comedias amorosas y de enredo, adaptadas festivamente y con 
una gran cantidad de bailes y motivos exóticos para el entretenimiento del público checoslovaco. El camino de la poesía, por su parte, tuvo un recorrido menor y permaneció unido a revistas especializadas y al interés por el género lírico de diferentes humanistas checoslovacos que investigaron y tradujeron antologías de los principales poetas mexicanos del siglo XX y trasladaron también a su ámbito cultural el creciente interés por los textos indígenas y la reescritura de un pasado conflictivo en el que ambas naciones se reconocieron y forjaron un importante espacio de encuentro.

\section{Bibliografía}

Barteček, I., Los textos de viajes diplomáticos de Vlastimil Kybal (México 1935 a 1936), Ibero-Americana Pragensia 38, 2004, pp. 111-123.

Bílková, E., Evropský literární klub, soupis nakladatelského archivu 1935-1949, Praga 1994.

Binková, S., Historia de las relaciones entre Bohemia y México en los siglos XVII y XVIII, Ibero-Americana Pragensia 18, 1984, pp. 67-93.

Cejka Luna, G., Escritores checos en México, Tamoanchan. Revista de Ciencias y Humanidades 3, 2013, pp. 1-19.

Crespo, H., El comunismo mexicano y la lucha por la paz en los inicios de la Guerra Fría, Historia mexicana 66/2, 2016, pp. 653-723.

Drahomíra Č., Evropský literární klub (ELK) a jeho místo v české knižní kultuře a v nakladatelském podnikání, Praga 1977.

Fernández Montes, J. O., Voces y llamamientos de la cultura por la paz: Génesis del pacifismo prosoviético de México en los albores de la Guerra Fría, Política y cultura 41, 2014, pp. 7-29.

Fuentes, C., La ciudad de Kafka y de Kundera: Praga y sus fantasmas, Tiempo de historia 8/90, 1 mayo 1982, pp. 52-63.

Fuentes, C., Los 68: París, Praga, México, Madrid 2005.

Fuentes, C., Nueve grandes textos sobre Julio Cortázar, La nación, 7 mayo 2000.

Gallardo-Saborido, E. et al., Cruzando el Puente Plateado: las relaciones culturales entre América Latina y el Bloque del Este, Revista de Letras 57/2, 2017, pp. 111-119.

Halada, J., Encyklopedie českých nakladatelství 1949-2006. Praga 2007.

Hammond, A. (ed.), The Palgrave Handbook of Cold War Literature, Cham 2020.

Hampejs, Z., El hispanismo en Checoslovaquia, Thesaurus 18/1, 1963, pp. 186-193.

Housková, A., Estudios de literatura latinoamericana en Checoslovaquia, Revista de crítica literaria latinoamericana 16/31-32, 1990, pp. 297-306.

Housková, A., Un puente plateado con América Latina: Zdeněk Šmíd, traductor, en: Las relaciones entre Europa Central y América Latina: Contextos históricos (ed. Opatrný, J.), Praga 2017, pp. 161-170. 
Housková, A et al, El hispanismo en las universidades checas, Praga 2010.

Kašpar O., Fechtnerová, A., Checos, moravos y silesios en el Nuevo Mundo en los siglos XVII y XVIII. Registro bio-bibliográfico, Annals of the Ndprstek Museum 15, 1988, pp. 165-204.

Kašpar O., Los jesuitas checos en la Nueva España, 1678-1767, México 1991.

Kašpar O., Los descubrimientos de ultramar y su eco en Bohemia, Praga 1992.

Kašpar O., El Nuevo mundo y el corazón de Europa, México 1997.

Kašpar O., La visión checa del nuevo mundo en los siglos XVI-XIX, Verba hispánica 12, 2004, pp. 59-68.

Kneidl, P. (ed.), Tratado sobre las nuevas tierras y el Nuevo Mundo, Praga 1981.

Locane, J., De la literatura latinoamericana a la literatura (latinoamericana) mundial, Berlín 2019.

Mamasalieva, E., La recepción del teatro latinoamericano en Checoslovaquia, Universidad Masaryk 2020 (Diploma de licenciatura).

Mendoza, M. L., Ra, Re, Ri, Ro, Rusia! La URSS, Ciudad de México 1974.

Molloy, S., La diffusion de la littérature hispano-américaine en France au XX siècle, París 1972.

Montoro Cano, E., El hispanismo en Checoslovaquia, Romanica Olomucensia 26/1, 2014, pp. 85-95.

Mudrovic, M. E., Mundo Nuevo. Cultura y Guerra Fría en la década del 60, Rosario1997.

Nemrava, D., Del boom a la bolañomanía en el campo literario checo: la creación y la transformación del canon literario en el contexto político de las últimas décadas del siglo XX, Cuadernos del CILHA 19/1, 2018, pp. 63-68.

Opatrný, J., Los temas de la iberoamericanística checa: pasado y perspectivas, Revista europea de estudios latinoamericanos y del Caribe 72, 2002, pp. 127-138.

Opatrný, J. (ed.), Las relaciones checo-mexicanas, Praga 2011.

Opatrný, J. (ed.), Las relaciones entre Europa Oriental y América Latina, 1945-1989, Praga 2015.

Opatrný, J. (ed.), Las relaciones entre Europa Central y América Latina, Contextos históricos, Praga 2017.

Opatrný, J. et al., Las relaciones entre Checoslovaquia y América Latina 1945-1989 en los archivos de la República Checa, Praga 2015.

Perutka, L., Checoslovaquia, Guatemala y México en el Período de la Revolución Guatemalteca, Praga 2014.

Río, M., La cripta del espejo, México 2019.

Rosenzweig, G. (ed.), Procurando contactos a la literatura mexicana. Alfonso Reyes-Zdênek Šmíd. Correspondencia (1932-1959), México 2014.

Rosenzweig, G., Historia de las primeras traducciones de novelas mexicanas (19281947), Literatura Mexicana 29/2, 2018, pp. 173-216. 
Rupprecht, T., Soviet Internationalism After Stalin, Cambridge 2015.

Sanchis Amat, V. M., 'Y todo esto pasó con nosotros'. Reescrituras del mundo indígena en la recepción literaria de Tlatelolco 1968, Madrid/Frankfurt 2020.

Servín, E., Propaganda y Guerra Fría: la campaña anticomunista en la prensa mexicana del medio siglo, Signos históricos 6/1, 2004, pp. 9-39.

Socorro Merlín, M., Catálogo comentado de la Obra de Emilio Carballido, Instituto Nacional de Bellas Artes y Literatura, [en línea], https://citru.inba.gob.mx/proyectos/investigacion/carballido/html/2.htm [Consulta: 05-08-2021].

Sudek, J. et al., Letra y fotografía en la vanguardia checa: Sutnar-Sudek y la editorial Druzstevní práce, Valencia 2006.

Ugarte, M. M., La posición de Federico Schroeder Inclán en el teatro mexicano contemporáneo, Los Ángeles 1971 (Disertación).

Uličný, M., Traducciones checas de poesía castellana, Livius 8, 1996, pp. 209-221.

Uličný, M., Historia de las traducciones checas de literaturas de España e Hispanoamérica, Praga 2005.

Uličný, M., Bibliografía de las traducciones checas de las literaturas de España e Hispanoamérica, 2005-2010, Ibero-Americana pragensia 44, 2016, pp. 113-121.

Volek, E., Octavio Paz en Checoslovaquia, Revista Iberoamericana 37/74, 1971, pp. 265-268.

Zourek, M., Checoslovaquia y el Cono Sur 1945-1989. Relaciones políticas, económicas y culturales durante la Guerra Fría, Praga 2015.

Zourek, M., Los viajes de los intelectuales latinoamericanos a Europa Oriental 19471956: organización, circuitos de contacto y reflexiones, Ars \& Humanitas 11/2, 2017, pp. 331-347.

Zourek, M., 2019. Praga y los intelectuales latinoamericanos, 1947-1959, Rosario 2019.

\section{Difusión y traducción de la literatura mexicana en Checoslovaquia durante la Guerra Fría}

Palabras clave: Guerra Fría, México, Checoslovaquia, literatura, traducción

El artículo pretende trazar una panorámica de la recepción de la literatura mexicana en Checoslovaquia durante los años de la Guerra Fría a partir del estudio de la difusión y la traducción de las obras literarias mexicanas que viajaron hasta las prensas checoslovacas de la mano de destacados mexicanistas. Durante estos años, la relación que entablaron intelectuales de los dos países motivó un florecimiento de la literatura 
mexicana en tierras europeas, forjándose un importante viaje de ida y vuelta en su estudio y recepción. Para el análisis de nuestro objeto de estudio partimos de la revisión de las relaciones institucionales y culturales entre ambos países, que antecede al comentario de las ediciones mexicanas publicadas en Checoslovaquia entre 1936 y 1979, con el objetivo de establecer una cronología de publicaciones de los diferentes géneros y abrir líneas de investigación acerca de las motivaciones de las principales obras mexicanas publicadas en Checoslovaquia.

\section{Razširjenost in prevajanje mehiške književnosti na Češkoslovaškem med hladno vojno}

Ključne besede: hladna vojna, Mehika, Češkoslovaška, književnost, prevajanje

Članek začrta panoramski pregled recepcije mehiške književnosti na Češkoslovaškem $\mathrm{v}$ letih hladne vojne na osnovi raziskave o razširjenosti in prevajanju mehiških književnih del, o katerih so v časopisju pisali priznani poznavalci Mehike. V tistih letih so odnosi, ki so jih navezali intelektualci obeh držav, v Evropi spodbudili razcvet mehiške literature ter njenega proučevanja in recepcije. Avtor začne analizo s pregledom institucionalnih povezav med državama, nato osvetli in kronološko razvrsti objave mehiških del na Češkoslovaškem med letoma 1936 in 1979 ter odpre smeri raziskovanja vzgibov za prevajanje najpomembnejših mehiških del v tem obdobju.

\section{The dissemination and translation of Mexican literature in Czechoslovakia during the Cold War}

Keywords: Cold War, Mexico, Czechoslovakia, literature, translation

This article aims to provide an overview of the reception of Mexican literature in Czechoslovakia during the years of the Cold War on the basis of a study of translations of Mexican literary works discussed in the Czechoslovak press by leading Mexicanists. During these years, strong relationships between intellectuals from the two countries helped raise the profile of Mexican literature in Europe by stimulating interest in its study and reception. This paper first reviews the institutional and cultural relations between both countries, then discusses the publication of Mexican 
literature in translation in Czechoslovakia between 1936 and 1979, establishing a chronology of publications in the different genres and exploring the motivations for the translation and publication of the main works of Mexican literature in Czechoslovakia during this period.

\section{O avtorju}

Víctor Manuel Sanchis Amat je doktoriral iz literarnih študij na Univerzi v Alicantu. Sodeluje v nacionalnih raziskovalnih projektih »Construction / reconstruction of the pre-Columbian and colonial world in the writing of women in Mexico (XIX-XXI centuries)« in »Latin American Writers in European Socialist Countries during the Cold War«. Je avtor monografij ' $Y$ todo esto pasó con nosotros'. Rewritings of the indigenous world in the literature on Tlatelolco 1968 (2020) in Francisco Cervantes de Salazar, a Humanist in New Spain in the 16th century (2016) ter sourednik monografij Raul Zurita: An Allegory of Desolation and Hope (2016) in The Literature of Independence and the Independence of Literature (2012). Objavil je tudi več člankov in poglavij v znanstvenih revijah in knjigah o starejši in sodobni latinskoameriški književnosti.

E-naslov: victor.sanchis@gcloud.ua.es

\section{About the author}

Víctor Manuel Sanchis Amat has a PhD in Literary Studies from the University of Alicante. He is a team member of the national research projects "Construction / reconstruction of the pre-Columbian and colonial world in the writing of women in Mexico (XIX-XXI centuries)", and "Latin American Writers in European Socialist Countries during the Cold War". He has published the following monographs: ' $Y$ todo esto pasó con nosotros'. Rewritings of the indigenous world in the literature on Tlatelolco 1968 (2020) and Francisco Cervantes de Salazar, a Humanist in New Spain in the 16th century (2016) and was a co-editor of the volumes Raul Zurita: An Allegory of Desolation and Hope (2016) and The Literature of Independence and the Independence of Literature (2012). He has also published article and chapters in various scholarly journals and edited books on viceregal and contemporary Latin American literature.

E-mail: victor.sanchis@gcloud.ua.es 